\title{
Evaluation on Spatial Adaptability of Historic Urban Blocks for Commercial Regeneration
}

\author{
Guopeng $\mathrm{Li}^{1 *}$, Yanbing Li ${ }^{2}$, Lingxi Wang ${ }^{1}$ \\ ${ }^{1}$ School of Architecture and Fine Arts, Dalian University of Technology, Dalian, China \\ ${ }^{2}$ School of Architecture and Art, Hebei University of Architecture, Zhangjiakou, China \\ Email: ^liguopeng@dlut.edu.cn
}

How to cite this paper: Li, G.P., Li, Y.B. and Wang, L.X. (2020) Evaluation on Spatial Adaptability of Historic Urban Blocks for Commercial Regeneration. Journal of Building Construction and Planning Research, 8, 203-216.

https://doi.org/10.4236/jbcpr.2020.83013

Received: June 22, 2020

Accepted: September 21, 2020

Published: September 24, 2020

Copyright $\odot 2020$ by author(s) and Scientific Research Publishing Inc. This work is licensed under the Creative Commons Attribution International License (CC BY 4.0).

http://creativecommons.org/licenses/by/4.0/

\begin{abstract}
In view of the current situation of aging, functional decline and protection difficulties in historic blocks, the feasibility of commercial regeneration is discussed. Referring to the relevant theories of protection and renewal of historic blocks, field investigation and expert consultation, fuzzy evaluation method and analytic hierarchy process are introduced to carry out a research study on the spatial adaptability of historic blocks for commercial regeneration and establish a preliminary evaluation system. An example of Dongguan Street Historic Block in Dalian is used to test the evaluation system. This provides a basis for the formulation of commercial regeneration strategy in the next stage.
\end{abstract}

\section{Keywords}

Historic Block, Commercial Regeneration, Adaptability, Evaluation System

\section{Introduction}

China has been undergoing unprecedentedly rapid changes, which is reflected by the large-scale construction in many cities. On the one hand, historic blocks as the carrier of urban culture are facing severe challenges. The interiors of historic blocks are badly damaged and are in dire need of renewal due to their long time past and lack of necessary protection and maintenance [1] [2]. On the other hand, to satisfy the needs of modern life, commercial activities are booming with greater and greater purchasing power. Against this background, the archaistic business zones in vulgar style that provide poor experience came into being [3]. Therefore, we should embark on commercial regeneration of the existing run-down urban historic blocks, preserve the original space while injecting vitality with new functions so as to form a benign industrial cycle. This should be 
considered as an effective strategy for the revival of the existing historic blocks, and it is conducive to the establishment of high-quality business blocks.

There are three types of related researches: 1) the study of the spatial morphology of historic blocks: to systematically analyze the characteristics of historic blocks to provide basic information for the reconstruction [4] [5] [6]; 2) the study of and empirical discussion about the corresponding design methods for different regeneration methods: to figure out the method from the theory and put forward effective reconstruction strategies according to the law [7] [8] [9]; 3) performance evaluation of the built environment of the commercial regeneration of historic blocks: to sort and summarize the actual condition after the completion of the project, analyze the shortcomings and symptoms and figure out the corresponding optimization strategies [10] [11] [12] [13]. In this paper, we try to build an initial evaluation system from the perspective of the research on the spatial adaptability of historic blocks for commercial regeneration that are less mentioned, hoping to explore the various factors that affect the commercial regeneration of historic blocks and promote scientific reconstruction.

\section{Evaluation Index of Spatial Adaptability of Historic Blocks for Commercial Regeneration}

The word "adapt" derives from the Latin ad (to) and aptare (fit) [14] and refers to adjustment and change. In the case of historical block, adaptability means the ability to adapt to a new application without compromising the original characteristics of a block. The spatial adaptability of historic blocks for commercial regeneration depends on the coordination among and dynamic development of various elements of the blocks, and restricts the specific modes of the reconstruction and renewal of historic blocks. The idea of introducing adaptability into construction building and planning research is to assist the decision-making process considering the sustainability and suitability for urban regeneration.

In Revitalizing Historic Urban Blocks, Tiesdell, Heath, and Oc [15] illustrated how to create a place in harmony with the context from different dimensions of the block with Glasgow business block, Denver LODO block and Shad Thames block as the examples; in Shanghai XINTIANDI Square-A Model of Old City Reconstruction, was analyzed and evaluated the regeneration in terms of overall planning, passages, edges, areas, nodes and markers [16]; in Performance of Commercial Renovation and Optimization of Historic Districts, Chen Meng [11] qualitatively evaluated the commercialization performance of Ningbo historic blocks from the perspectives of space, culture, economy, facilities, society et al. and explained the reasons for its low performance.

The above researches show that there are complex and diverse factors influencing the adaptability of historic blocks for commercial regeneration. They may include spatial elements such as block environment and street buildings, social factors such as block development and government guidance. Different factors have different effects. In this paper, we mainly study the spatial elements. In order to have an overall cognition of material aspects of the block and guarantee 
reasonable and feasible evaluation indexes when establishing the evaluation system, we select and supplement the elements in line with the following principles:

- Principle of science: the indexes should be scientific, normative and representative, independent from each other with weak correlation;

- Principle of operability: the effectiveness and operability of indexes should be guaranteed in practical application, so that they are easy to collect, sort out, differentiate and quantify;

- Principle of hierarchy: the indexes should be classified into different levels from top to bottom according to their relations of juxtaposition or inclusion, so as to avoid logic ambiguity and disorder in subordination relations among the indexes;

- Principle of comprehensiveness: the indexes should cover a complete evaluation system and avoid one-sidedness.

According to the research system of Analytic Hierarchy Process [17] [18] [19], in the first level of evaluation indexes, we should list and layer-by-layer subdivide the five types of indexes including external environment, overall situation, internal street and lane space, landscape nodes and markers and internal buildings of historic blocks from macroscopic level to microcosmic level.

- External environment of historic blocks: the historic blocks as part of urban space have undergone long-term development and change. They have a lot to do with the surroundings. The external environment consisting of spatial location, traffic conditions, surrounding conditions. determines the block's commerce carrying capacity and potential commercial value at the city level, and affects the commercial regeneration of the block;

- Overall situation of historic blocks: as an internal factor, the situation itself plays a decisive role in the spatial adaptability. The group scale of a historic block is related to the input and output of regeneration, the regeneration method and the corresponding commercial type after the regeneration; the openness of a historic block determines its communication with the outside world and whether it is easy to be perceived by the crowd; the overall spatial layout reflects the spatial organization and order relationship of the building and affects its fit with the commercial functional organization; the internal flow affects the security, orderliness and commercial enjoyment;

- Internal street and lane space: the streets and lanes enclosed by the threedimensional interface are the basic skeleton of the historical block, the main carrier of people's behavior and activities after commercial regeneration, and an important index of spatial adaptability. In The Aesthetic Townscape, Yoshinobu Ashihara [20] analyzes the internal street and lane space from the perspectives of the shape (sinuosity), interface, dimensions and scale of street and lane;

- Landscape nodes and markers: as a point space different from linear streets and lanes, abundant and orderly nodes are important resources for commercial regeneration and are beneficial to the formation of an active and prosperous block atmosphere. The signs along the streets help pedestrians to de- 
velop a clear impression of the block and are conducive to determining the focus of commercial regeneration;

- Internal buildings: internal buildings, streets and lanes, and nodes and markers, are the concrete material presentation of a historic block. The building quality, design and decoration of historic blocks all affect the value and vitality of the block; and it is not easy to meet the requirements through brief reconstruction.

According to the theoretical literature in historic blocks morphological characteristics, reconstruction and renewal, value assessment, commercial street design, adaptation of urban blocks and other related fields as well as practice research studies on the historic blocks, in combination with the classification principle of Analytic Hierarchy Process, we reorganize a logical relationship of evaluation objectives, comprehensive evaluation, factor evaluation and element evaluation towards the identified evaluation index group, and formulate the Evaluation System of Spatial Adaptability of Historic blocks for Commercial Regeneration. Through integration, it is divided into five comprehensive evaluation layer indexes, 16-factor evaluation layer indexes and 20-element evaluation layer indexes as illustrated (Table 1).

Table 1. Hierarchy system of evaluation index group of spatial adaptability of historic blocks for commercial regeneration.

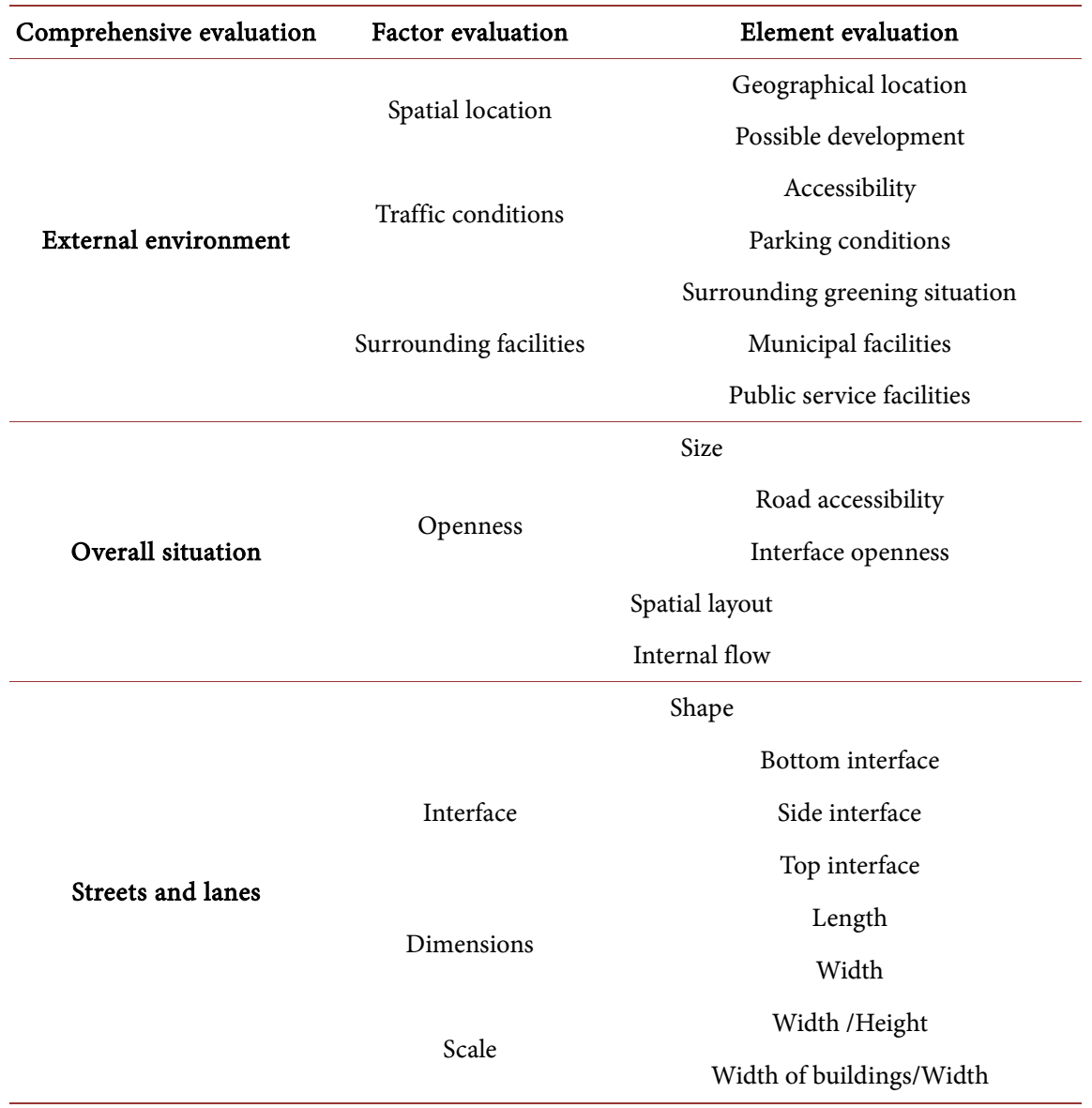




\section{Continued}

\begin{tabular}{|c|c|c|}
\hline $\begin{array}{l}\text { Landscape nodes and } \\
\text { markers }\end{array}$ & \multicolumn{2}{|c|}{ Nodes } \\
\hline \multirow{3}{*}{ Buildings } & \multicolumn{2}{|c|}{ Building quality } \\
\hline & Building Design & $\begin{array}{c}\text { Form layout } \\
\text { Structural materials }\end{array}$ \\
\hline & Building decoration & $\begin{array}{l}\text { Building style } \\
\text { Building details }\end{array}$ \\
\hline
\end{tabular}

\section{Evaluation System of Spatial Adaptability of Historic Blocks for Commercial Regeneration}

\subsection{Perspectives and Methods of Evaluation}

This paper emphasizes on the spatial elements of historic blocks for the evaluation of spatial adaptability. Currently, the research of street-block space and the design of commercial space are all based on mature theories. Therefore, we use the following methods in a specific evaluation process though theoretical judgment combined with an evaluation of a small number of subjects:

- For data acquisition, we mainly adopt the method of literature research combined with field research, so as to get the theoretical basis of evaluation standards and accurate data of empirical cases. In a specific survey, the methods including observation, mapping, scaling, summary and induction are adopted;

- Data analysis and evaluation: The methods used in data analysis and evaluation include the follows:

1) Qualitative and quantitative analysis: carry out the qualitative judgment on the evaluation objects and quantitative translation based on the results;

2) Analytic Hierarchy Process: decompose the index group into objective layer, comprehensive layer, factor layer and element layer for evaluation and weight calculation;

3) Delphi method: for the weight calculation, get the experts' judgment on the importance of evaluation indexes by issuing consulting questionnaires and then calculated the weight of indexes;

4) Fuzzy evaluation method: for the result analysis, rank and evaluate the various indexes of the evaluation object according to the obtained scores based on the fuzzy mathematical principle;

5) Comprehensive evaluation method: "integrate" the evaluation index values of different aspects into an overall comprehensive evaluation value to obtain direct evaluation results.

\subsection{Determination of Index Weight}

Different influence indexes have different influences on the adaptability historic blocks for commercial regeneration. Therefore, determining the weight of influence indexes is the key step to build a scientific and complete model for an 
evaluation and finish the overall assessment. In this paper, we determine the weight of influence indexes through case analysis studies and expert consultations and interviews, with the following main steps:

- Select the domestic typical reconstruction cases of appropriate scale and great influence such as Shanghai Tian Zi Fang, XINTIANDI and Nanjing 1912, study the commercial regeneration methods, reconstruction process and the space, culture and economy of these historic blocks after commercial regeneration, analyze the role of all elements during the reconstruction and preliminarily determine the importance of each index in commercial regeneration.

- Formulate the expert consulting questionnaires according to the influence indexes, and distribute them to the architectural and urban planning related professors in colleges and universities, architects in design institutes and subject relevant staff in business and historic preservation departments in local government. Valid questionnaires (94 out of 100) were collected. And then the expert consultation weights of different evaluation indexes according to the results of the consulting questionnaires were calculated with the Analytic Hierarchy Process software YAAHP, and verify the rationality through consistency testing.

- Compare the results of preliminary weight of empirical analysis and weight of expert consultation, and get the final weight through fine adjustment and integration. The model for spatial adaptability evaluation is composed of influence evaluation indexes from Hierarchy System of Evaluation Index Group and their weights (100 in total), shown in Table 2.

\subsection{Evaluation Grade and Scoring Criteria}

In order to quantify the evaluation indexes, we divide the evaluation indexes into four scores levels ( 0 - 2 points, 3 - 5 points, 6 - 8 points, 8 - 10 points), by referring to the scoring standards of the existing relevant evaluation system and combining with the design theory and the overall characteristics of historic urban blocks, to realize a certain degree of differentiation and ensure the implementation of the evaluation. It's very difficult for China with a vast territory to establish a unified evaluation standard due to its numerous and distinctive historical districts affected by different factors. In this study, we try to establish the reference basis based on its generality (shown in Table 2). During the in-depth study of one specific historic block, we should determine the scoring standard through modification and adjustment according to the characteristics of the historic block.

\subsection{Application of Evaluation Results}

According to the evaluation and quantification results, which theoretically could go from 0 to 1000 aggregate scores, we divide the adaptability levels into Grade A, B, C and D. From A to D, the overall adaptability decreases, and the corresponding methods and strategies of commercial regeneration should be different. 
Table 2. Evaluation system of spatial adaptability of historic blocks for commercial regeneration.

\begin{tabular}{|c|c|c|c|c|c|c|c|c|c|}
\hline \multicolumn{6}{|c|}{ Evaluation Index } & \multicolumn{4}{|c|}{ Score } \\
\hline & Weight & $\begin{array}{c}\text { Factor } \\
\text { evaluation }\end{array}$ & Weight & $\begin{array}{c}\text { Element } \\
\text { evaluation }\end{array}$ & Weight & $0-2$ & $3-5$ & $6-8$ & $8-10$ \\
\hline \multirow{7}{*}{$\begin{array}{c}\text { External } \\
\text { environment }\end{array}$} & \multirow{7}{*}{20} & & & $\begin{array}{c}\text { Geographical } \\
\text { location }\end{array}$ & 6 & $\begin{array}{l}\text { Remote village or } \\
\text { outer suburbs of a city }\end{array}$ & $\begin{array}{l}\text { Outskirts of a city } \\
\text { or edge of a district }\end{array}$ & Center of a district & Center of a city \\
\hline & & $\begin{array}{l}\text { Spatial loca- } \\
\text { tion }\end{array}$ & 10 & $\begin{array}{c}\text { Possible } \\
\text { development }\end{array}$ & 4 & $\begin{array}{l}\text { Two points for each fac } \\
\text { important transportati } \\
\text { community }\end{array}$ & $\begin{array}{l}\text { ict: proximity to busin } \\
\text { ion node, important } p\end{array}$ & $\begin{array}{l}\text { ness circle, historical } \\
\text { public facilities and la }\end{array}$ & $\begin{array}{l}\text { and cultural area, } \\
\text { arge living }\end{array}$ \\
\hline & & Traffic & & Accessibility & 5 & $\begin{array}{l}\text { Inconvenient access } \\
\text { and poor accessibility }\end{array}$ & $\begin{array}{l}\text { Ordinary } \\
\text { accessibility }\end{array}$ & Good accessibility & $\begin{array}{l}\text { A variety of traffic } \\
\text { and great } \\
\text { accessibility }\end{array}$ \\
\hline & & conditions & 0 & $\begin{array}{l}\text { Parking } \\
\text { conditions }\end{array}$ & 1 & $\begin{array}{l}\text { Extremely difficulty in } \\
\text { parking }\end{array}$ & $\begin{array}{l}\text { No parking } \\
\text { facilities, Roadside } \\
\text { parking }\end{array}$ & $\begin{array}{l}\text { Inadequate } \\
\text { parking facilities, } \\
\text { random parking }\end{array}$ & $\begin{array}{l}\text { Adequate facilities, } \\
\text { convenient parking }\end{array}$ \\
\hline & & & & $\begin{array}{l}\text { Surrounding } \\
\text { greening } \\
\text { situation }\end{array}$ & 1 & $\begin{array}{l}\text { Little green landscape } \\
\text { and poor } \\
\text { environmental quality }\end{array}$ & $\begin{array}{l}\text { Little green } \\
\text { landscape and } \\
\text { ordinary } \\
\text { environmental } \\
\text { quality }\end{array}$ & $\begin{array}{l}\text { Much green } \\
\text { landscape and good } \\
\text { environmental } \\
\text { quality }\end{array}$ & $\begin{array}{l}\text { Much green } \\
\text { landscape and } \\
\text { excellent } \\
\text { environmental } \\
\text { quality }\end{array}$ \\
\hline & & $\begin{array}{l}\text { Surrounding } \\
\text { facilities }\end{array}$ & 4 & $\begin{array}{l}\text { Municipal } \\
\text { facilities }\end{array}$ & 2 & $\begin{array}{l}\text { Two points for each of } \\
\text { facilities }\end{array}$ & f water supply, electric & city, heating, gas and & other additional \\
\hline & & & & $\begin{array}{c}\text { Public } \\
\text { service } \\
\text { facilities }\end{array}$ & 1 & $\begin{array}{l}\text { Few types and } \\
\text { insufficient quantity } \\
\text { of facilities }\end{array}$ & $\begin{array}{l}\text { Few types and } \\
\text { ordinary quantity of } \\
\text { facilities }\end{array}$ & $\begin{array}{l}\text { Many types and } \\
\text { f ordinary quantity of } \\
\text { facilities }\end{array}$ & $\begin{array}{l}\text { Many types and } \\
\text { f abundant quantity } \\
\text { of facilities }\end{array}$ \\
\hline \multirow{5}{*}{$\begin{array}{l}\text { Overall } \\
\text { situation }\end{array}$} & \multirow{5}{*}{28} & Size & 3 & & & & $\begin{array}{l}\text { Super-large } \\
\text { historical block with } \\
\text { an area more than } \\
60 \text { ha }\end{array}$ & $\begin{array}{l}\text { Small and } \\
\text { medium-sized } \\
\text { historical block with } \\
\text { an area less than } 10 \\
\text { ha }\end{array}$ & $\begin{array}{l}\text { Ordinary historical } \\
\text { block with an area } \\
\text { between } 10 \text { ha and } \\
60 \text { ha }\end{array}$ \\
\hline & & & & $\begin{array}{c}\text { Road } \\
\text { accessibility }\end{array}$ & 5 & $\begin{array}{l}\text { Not adjacent to } \\
\text { urban road }\end{array}$ & $\begin{array}{l}\text { Only adjacent to } \\
\text { urban branch road }\end{array}$ & $\begin{array}{l}\text { Adjacent to urban } \\
\text { secondary main } \\
\text { road }\end{array}$ & $\begin{array}{l}\text { Adjacent to urban } \\
\text { main road }\end{array}$ \\
\hline & & Openness & 10 & $\begin{array}{l}\text { Interface } \\
\text { openness }\end{array}$ & 5 & $\begin{array}{l}\text { Dominated by wall } \\
\text { interface; } \\
\text { The block is closed }\end{array}$ & $\begin{array}{l}\text { Dominated by } \\
\text { building interface; } \\
\text { Moderate openness }\end{array}$ & $\begin{array}{l}\text { More greening } \\
\text { interfaces; } \\
\text { Good openness }\end{array}$ & $\begin{array}{l}\text { More square node } \\
\text { interfaces; excellent } \\
\text { openness }\end{array}$ \\
\hline & & Spatial layout & 12 & & & $\begin{array}{l}\text { Promiscuous space } \\
\text { and disordered } \\
\text { arrangement }\end{array}$ & $\begin{array}{l}\text { The pattern layout fo } \\
\text { independent centrip } \\
\text { type, the traditional } \\
\text { type and so on, each } \\
\text { Therefore, it is neces } \\
\text { conditions. }\end{array}$ & $\begin{array}{l}\text { orms include linear a } \\
\text { etal type, the homog } \\
\text { courtyard type and } \\
\text { with its own merits } \\
\text { ssary to judge based }\end{array}$ & $\begin{array}{l}\text { Irrangement type, the } \\
\text { seneous structure } \\
\text { he group centripetal } \\
\text { and demerits. } \\
\text { on the specific }\end{array}$ \\
\hline & & Internal flow & 5 & & & $\begin{array}{l}\text { Mixing of pedestrians } \\
\text { and vehicles, and } \\
\text { crossing between } \\
\text { inside and outside }\end{array}$ & $\begin{array}{l}\text { Separation of } \\
\text { pedestrians from } \\
\text { vehicles, and } \\
\text { crossing between } \\
\text { inside and outside }\end{array}$ & $\begin{array}{l}\text { Mixing of } \\
\text { pedestrians and } \\
\text { vehicles, and } \\
\text { separation of inside } \\
\text { from outside }\end{array}$ & $\begin{array}{l}\text { Separation of } \\
\text { pedestrians from } \\
\text { vehicles, and } \\
\text { separation of inside } \\
\text { from outside }\end{array}$ \\
\hline \multirow[b]{2}{*}{$\begin{array}{l}\text { Streets and } \\
\text { lanes }\end{array}$} & \multirow[b]{2}{*}{24} & Shape & 3 & & & Long straight path & Short straight path & Broken line path & Curved path \\
\hline & & Interface & 8 & $\begin{array}{l}\text { Bottom } \\
\text { interface }\end{array}$ & 2 & $\begin{array}{l}\text { No pavement, } \\
\text { discomfort }\end{array}$ & $\begin{array}{l}\text { Monotonous } \\
\text { pavement, } \\
\text { discomfort in } \\
\text { gradient }\end{array}$ & $\begin{array}{l}\text { Monotonous } \\
\text { pavement, safety } \\
\text { and comfort }\end{array}$ & $\begin{array}{l}\text { Exquisite pavement, } \\
\text { safety and comfort }\end{array}$ \\
\hline
\end{tabular}




\section{Continued}

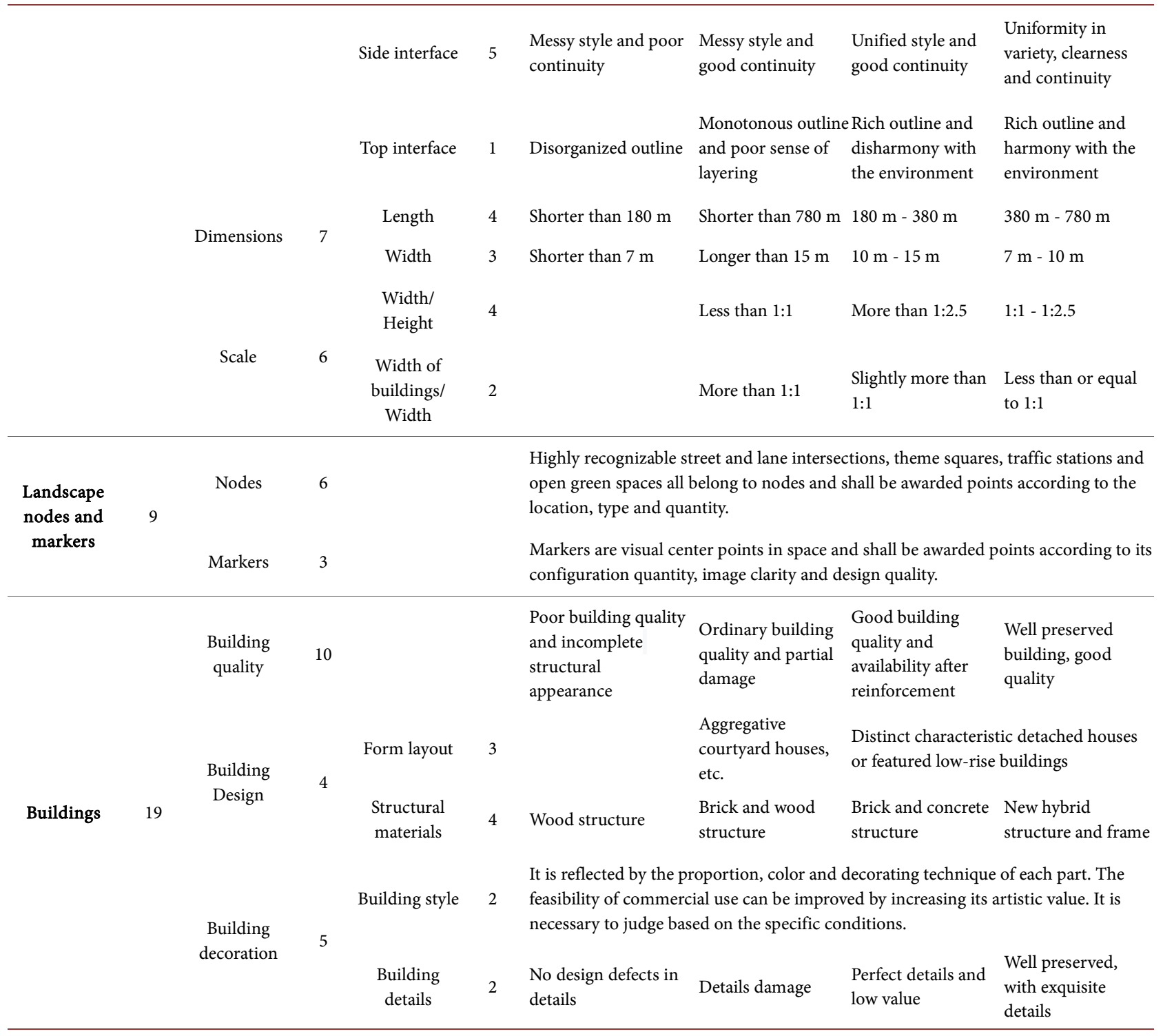

If the evaluation result falls in Grade A (Aggregate score: 801 - 1000), it means that one historic block is highly compatible with commercial requirements. Therefore, it is suggested extending the vitality of the historic block through commercial regeneration. For specific implementation, the low-intensity development mode can be also adopted, to preserve the spatial structure and texture of the whole area as much as possible, respect the original appearance of the historical buildings, and conduct local small-scale renovation and progressive renewal to meet the requirements of modern business.

If the evaluation result falls in Grade B (Aggregate score: 501 - 800), it means that the adaptation of commercial regeneration of the block is strong. Therefore, it is suggested using commercial measures to properly transform the area to meet commercial functional requirements and achieve reservation of exterior and commerce replacement, on the basis of maintaining the overall style and 
building appearance of the block.

If the evaluation result falls in Grade C (Aggregate score: 201 - 500), it means that there are many problems in the historic block itself and even some major defects, and it is not suitable for commercial regeneration, from the perspective of commercial requirements. For specific implementation, high-intensity development may be required, which can be achieved through a large-scale restoration or even antique reconstruction while maintaining the same style and features.

If the evaluation result falls in Grade D (Aggregate score: 0 - 200), it means that one historic block is basically not suitable for commercial regeneration. Specifically, it may be due to the quality problem itself (for example, much damage has been done to the urban texture or buildings) or the huge difference between the features of the historic block and the commercial functional requirements and great difficulty in remedy through reconstruction.

\section{Empirical Evaluation of Dalian Dongguan Street Historic Block}

In this paper, we try to apply the Spatial Adaptability Evaluation model to Dalian Dongguan Street Historic Block. Dongguan Street Historic Block is located in the center of Dalian City, Xigang District. In 1889, it was planned, with the drawing and concept formed, as a market street of Chinese by Tsarist Russia. In 1905, high-density multi-floor courtyard houses were built here for Chinese laborers to live in. In 1930, it became a gathering place for Chinese merchants (Figure 1 shows the commercial atmosphere of Dongguan Street at that time). In 1945, it was classified into Xigang District as a residential area till now. It is now on the reconstruction schedule due to the decline in the overall quality. In 2017, proposals for the protection of historical buildings in Dalian Dongguan Street were solicited from the whole country.

Through the qualitative judgment, quantitative translation and statistics accounting of the adaptability of commercial regeneration of various parts of Dalian Dongguan Street Historic Block according to the evaluation system and scoring criteria, this research group graded each of the evaluation index and got the results as follows (Table 3):

The score of external environment is 168 (200 in total $\left.{ }^{1}\right)$. The advantageous urban location (Figure 2) and traffic conditions make up for the deficiency in surrounding facilities. Afterwards, the surrounding facilities can be improved to some degree, such as increasing necessary municipal utilities and facilities (gas, water supply and drainage, lighting, public toilets, garbage stations and barrier-free facilities) and creating positive space through landscape planting.

The score of overall situation is 190 (280 in total). The Dalian Dongguan Street Historic Block features an appropriate size, high degree of openness and distinct spatial layout is easy to become a reticulate commercial street. Figure 3

${ }^{1}$ The total score of each evaluation index is calculated by multiplying the weight by the score. Taking external environment as an example, the weight is 20 , and the highest score is 10 , the total score of external environment is 200 . 


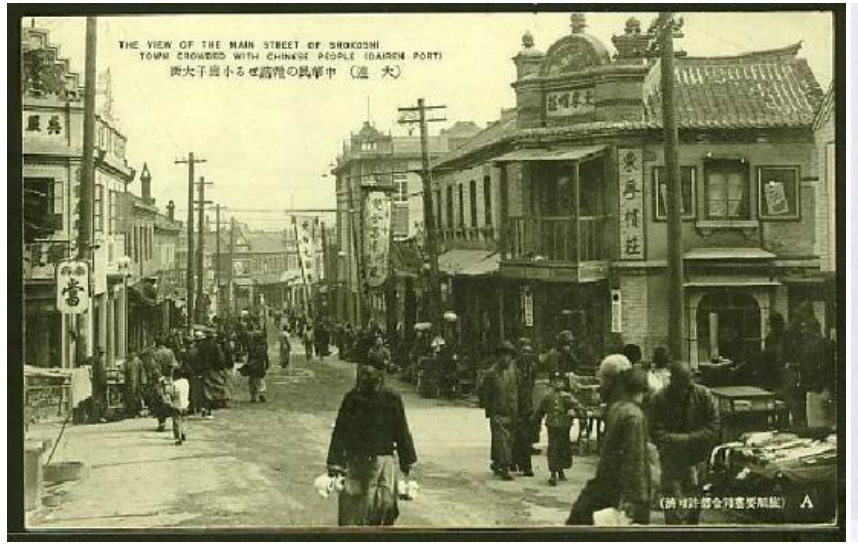

(a)

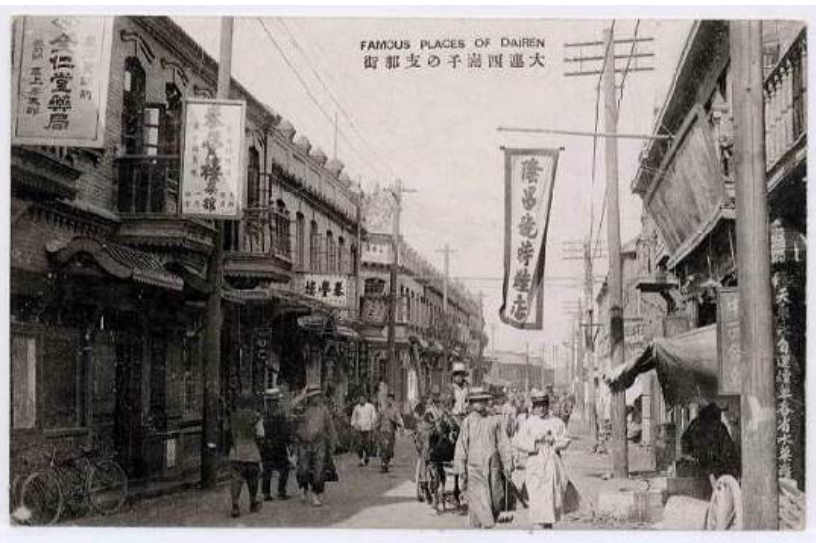

(b)

Figure 1. Old pictures of Dalian Dongguan Street [21]: (a) The view of the main street of Shokoshi Town (Japanese for Xiaogangzi District, where Dongguan Street was located in) crowded with Chinese people; (b) Famous places of Dalian-Market Street for Chinese.

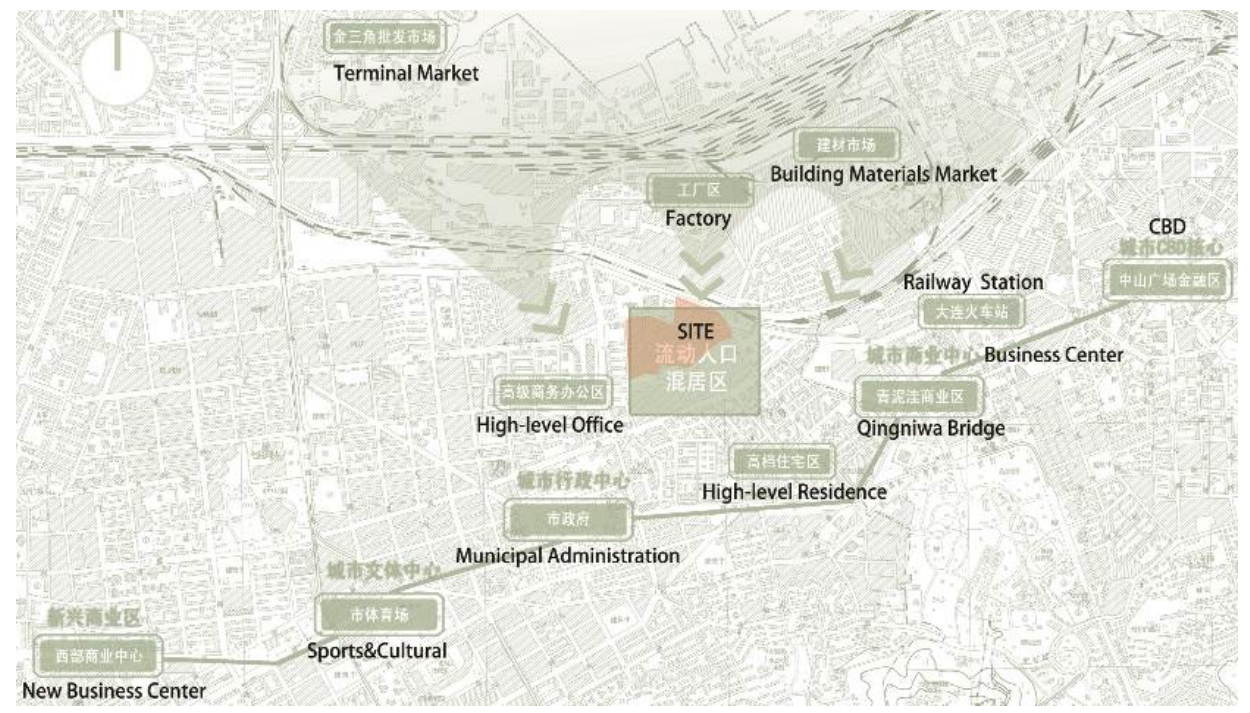

Figure 2. The urban location of Dalian Dongguan Street: the central part in Dalian City, Liaoning Province, China, near Dalian Railway Station and City Government.

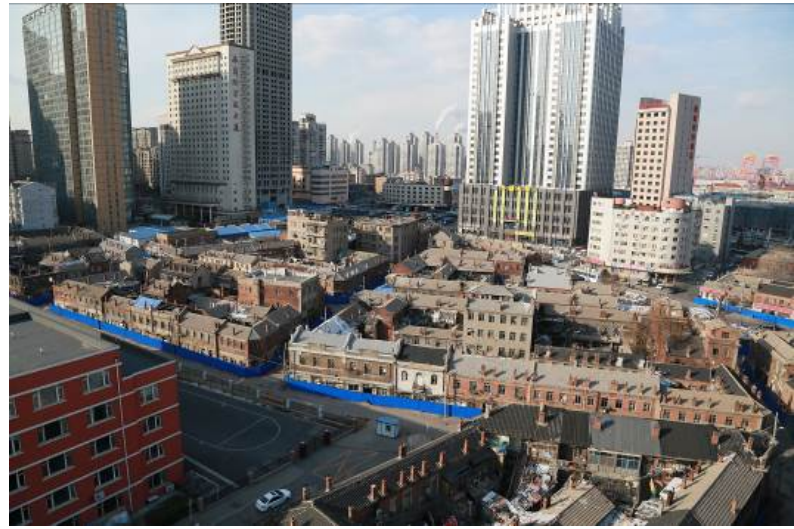

(a)

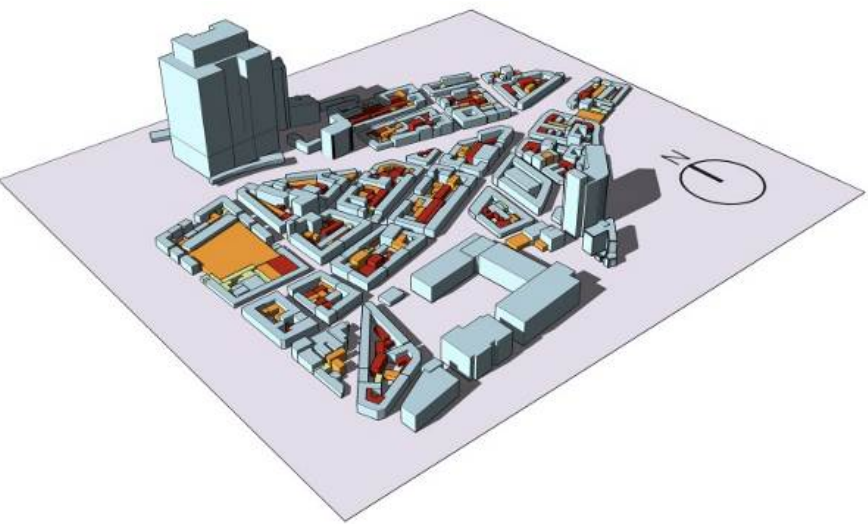

(b)

Figure 3. The overall condition of Dalian Dongguan Street Historic Block (a) Bird view; (b) The texture of streets and buildings. 
Table 3. Evaluation of Sptial adaptability of Dalian Dongguan street historic block.

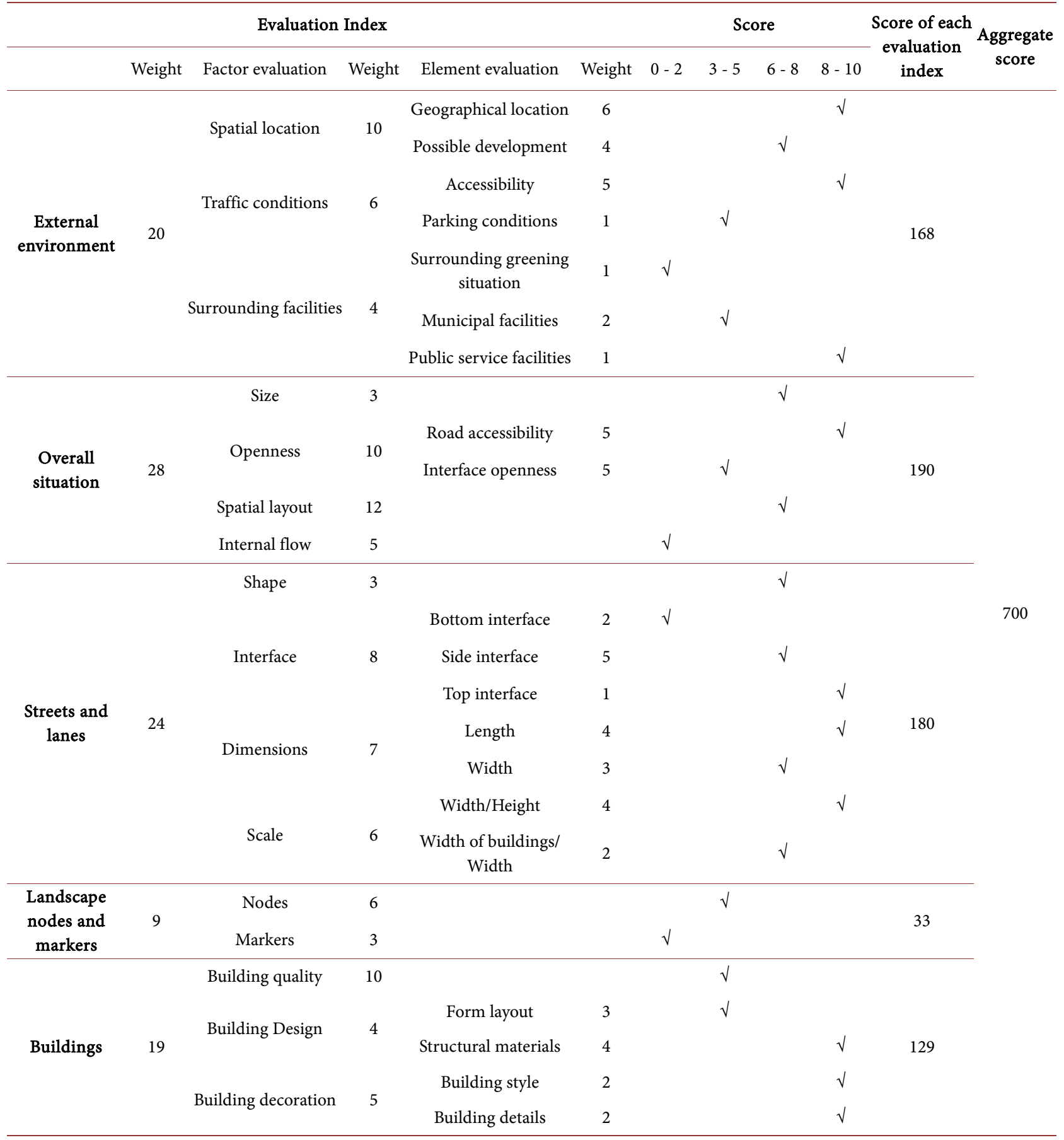

shows the overall condition of Dalian Dongguan Street Historic Block. But at present, the internal flow is disordered, which makes it less conducive to reconstruction. Under this background, it is feasible to redesign the main and secondary axes, core nodes and different functional areas of Dongguan Street to knit up and integrate the existing messy texture on this basis; it is also recommended to reorganize traffic for vehicles and pedestrian flow and set up a number of parking facilities on one side of the road. The block interface on the main direction 
of people flow can be opened towards the city, attracting the flow of people with a entrance square, green plant landscape and landmark structures.

The score of internal streets and lanes is 180 (240 in total). The shape, proportion and scale of streets and lanes in the block (Figure 4) are suitable for people to walk and communicate, which is interesting and pleasant. The block features poor bottom interface and less open side interface.

The score of landscape nodes and markers is 33 (90 in total). The building density of the block is high, and the orderly and homogeneous street space enclosed by the multi-storey building group bears all the public activities of the people. There is neither node space planned and designed within the block, nor iconic buildings or structures of distinctive images, except one six-storey building.

The score of buildings is 129 (190 in total). The building quality in the block is ordinary, and the main structure of some buildings is destroyed, restricting its application in practical commercial regeneration. With the style and details of high artistic value and obvious characteristics of the times (Figure 5), the buildings are recognizable in the city with overwhelming modern architecture. In the

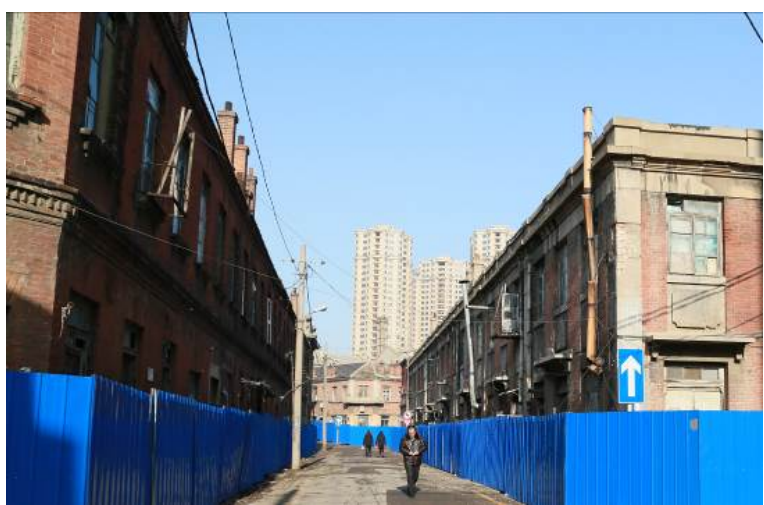

(a)

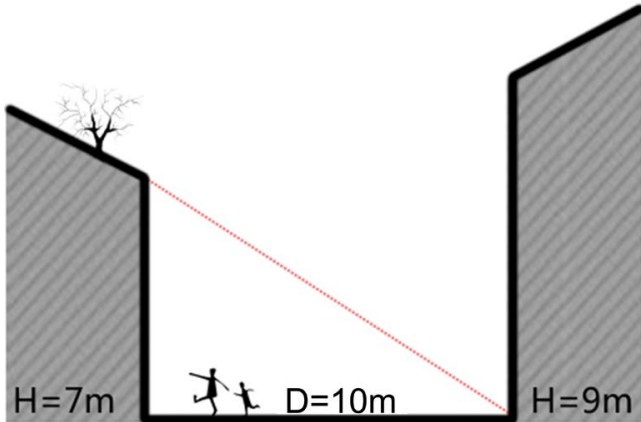

$1.1<\mathrm{D} / \mathrm{H}<1.4$

(b)

Figure 4. Evaluation of streets and lanes of Dongguan Street Historic Block: (a) Current condition of streets and lanes; (b) The street scale is mostly between 1.1 and 1.4, which is within a decent range.

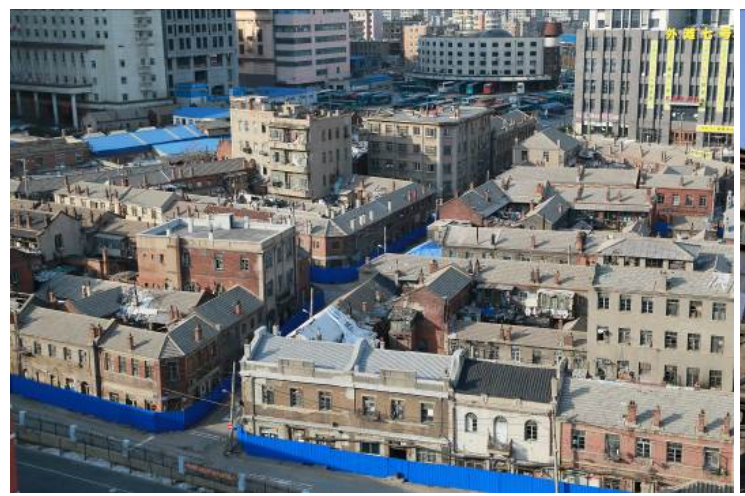

(a)

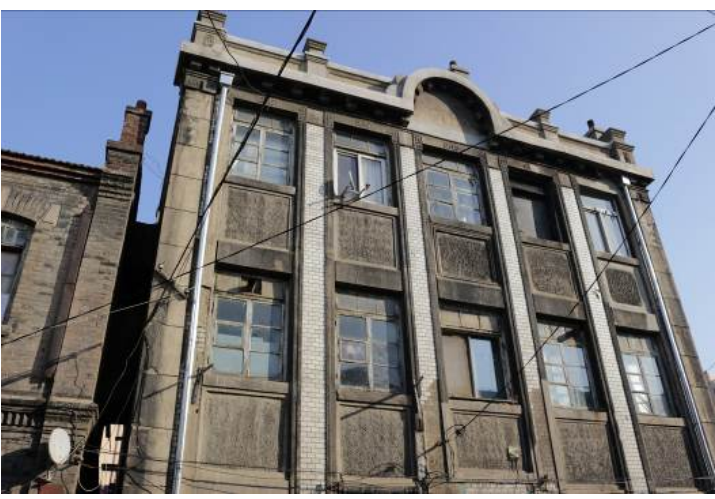

(b)

Figure 5. The building quality in Dongguan Street Historic Block: (a) Old but distinctive courtyard houses and low-rise buildings; (b) stylish building façade with details and decorations 
regeneration, specific design can be conducted with reference to the existing reconstruction examples in combination with the evaluation results.

The spatial adaptability of Dongguan Street Historic Block for commercial regeneration scores 700 out of 1000 in total, falling in Grade B of the evaluation system. Thus, it has strong adaptability for commercial regeneration. Self-renewal of the block can be considered through commercial function implantation while maintaining the overall style and features of the whole area. In Dongguan Street Historic Block, as an area where Chinese people lived under colonial domination in modern times, many old and famous shops with strong brand effects still exist now, in addition to the typical modern residential buildings. According to the superior location and the characteristic of Dalian City as a tourism city, Dongguan Street Historic Block can be transformed into a characteristic tourism and commercial pedestrian street dominated by old business and supplemented by leisure entertainment and catering in terms of function.

\section{Conclusion}

Historic blocks unavoidably face challenges from the present and the future. One way out for most historic blocks is to carry out necessary protection, restoration and renovation to embrace new functions. In this paper, we have introduced the method to establish an evaluation system of spatial adaptability of historic blocks for commercial regeneration, both qualitatively and quantitatively on the basis of abundant literature study, consulting interviews and field investigations. Taking Dalian Dongguan Street as an example, we have discussed the application of the evaluation system from the specific operation level and checked its rationality and operability, with the hope to provide solutions for the issues encountered in the renovation and reconstruction of historic blocks.

\section{Acknowledgements}

The authors thank the teachers and students in Design Workshop 2015 held by Dalian University of Technology and Tokyo Denki University for providing initial investigation material of Dongguan Street and the professors and architects for assistance with questionnaires to determine the weight of each evaluation index. This research was supported by Open Projects Fund of Key Laboratory of Ecology and Energy-saving Study of Dense Habitat (Tongji University), Ministry of Education, Project Number: 201830202; and the Fundamental Research Funds for the Central Universities, Grant Number: DUT19RW113.

\section{Conflicts of Interest}

The authors declare no conflicts of interest regarding the publication of this paper.

\section{References}

[1] Sui, Q., Zhang, F., Matsumura, S. and Nizawa, T. (1995) The Architectural Heritage of Modern China: Dalian. China Architecture \& Building Press, Beijing. 
[2] Jiang, L. (1999) Colonial Residential Building of Dalian. Journal of Shenyang Architectural and Civil Engineering Institute, 15, 195-200.

[3] Li, G., Zhu, Q., Li, Y. and Liu, J. (2016) Adaptable Strategies on the Regeneration of Historical Urban Centre. International Conference on Social Design and Resilient Sustainable Planning, Taipei, 11 March 2016, C-10.

[4] Duan, J. and Ji, S. (2015) Spatial Research Review of Ancient Towns in Taihu Basin. Rural Planning and Construction, No. 3, 37-54.

[5] Hu, M. and Dong, W. (2004) Research on the Application of GIS Technology in Historic Block Protection Planning. Architectural Journal, 12, 63-65.

[6] Xia, Q., Xu, X., Xu, M. and Cui, N. (2012) Analysis on the Spatial Form and Style Features of the Five Avenues Historical Area in Tianjin. Journal of Tianjin University (Social Sciences), No. 2, 150-155.

[7] Oc, T., Health, T. and Tiesdell, S. (2010) Design in Historic Urban Blocks. https://www.ledonline.it/Rivista-Scienze-Turismo/Allegati/RST-I-2-04-Oc-Heath-T iesdell.pdf

[8] Shi, Y. and Huang, Y. (2016) Spatial Rebuilding in Renewal and Reconstruction of Historic Block-Taking Shanghai XINTIANDI and Tian Zi Fang as Examples. Papers Collection of the 2016 Annual Conference on Urban Planning of Chinese Cities, Shenyang, 24 September 2016, 308-317.

[9] Xu, J. (2016) Commercial Reform of Historical and Cultural Districts-A Case Study of Nanjing 1912 Theme District. Architecture \& Culture, No. 8, 154-155.

[10] Wang, Y. and Li, X. (2015) Research on Public Evaluation of Commercial Reform of Historical and Cultural Blocks-A Case Study of "Nanjing 1912". Huazhong Architecture, No. 8, 27-30.

[11] Chen, M., Wu, Y. and Wu, C. (2013) Performance of Commercial Renovation and Optimization of Historical Districts. Planners, 10, 86-90+96.

[12] Ruan, Y. and Gu, X. (2004) An Analysis about the Practical Patterns to Conserve the Historic Districts in China. Journal of Tongji University Social Science Section, No. 5, 1-6.

[13] Liang, Q. and Hu, S. (2007) Evaluation on the Quality of Protected Built Environment of Historic Districts. Architectural Journal, No. 6, 66-68.

[14] Douglas, J. (2002) Building Adaptation. Butterworth-Heinemann, Oxford.

[15] Tiesdell, S., Taner, O. and Heath, T. (1996) Revitalizing Historic Urban Blocks. Architectural Press, Oxford.

[16] Luo, X. (2001) XINTIANDI, One of the Mode of Urban Revitalization. Time + Architecture, No. 4, 24-29.

[17] Ho, W. and Ma, X. (2018) The State-of-the-Art Integrations and Applications of the Analytic Hierarchy Process. European Journal of Operational Research, 267, 399-414. https://doi.org/10.1016/j.ejor.2017.09.007

[18] Saaty, T.L. and Vargas, L.G. (2012) Models, Methods, Concepts \& Applications of the Analytic Hierarchy Process. Springer, New York. https://doi.org/10.1007/978-1-4614-3597-6

[19] Forman, E.H. and Gass, S.I. (2001) The Analytic Hierarchy Process-An Exposition. Operations Research, 49, 469-486. https://doi.org/10.1287/opre.49.4.469.11231

[20] Ashihara, Y. (1983) The Aesthetic Townscape. MIT Press, Cambridge.

[21] Dalian City Memory: Dongguan Street Old Buildings. http://blog.sina.com.cn/s/blog_4cd69daf0102efuw.html 